Open Access

\title{
Plasmodium falciparum coronin organizes arrays of parallel actin filaments potentially guiding directional motility in invasive malaria parasites
}

\author{
Maya A Olshina 1,2, Fiona Angrisano 1,2, Danushka S Marapana ${ }^{1,2}$, David T Riglar 1,2,9, Kartik Bane 3 , \\ Wilson Wong ${ }^{1,2}$, Bruno Catimel ${ }^{4,10}$, Meng-Xin Yin ${ }^{5}$, Andrew B Holmes ${ }^{5}$, Friedrich Frischknecht ${ }^{3}$, David R Kovar ${ }^{6,7}$ \\ and Jake Baum ${ }^{1,2,8^{*}}$ (])
}

\begin{abstract}
Background: Gliding motility in Plasmodium parasites, the aetiological agents of malaria disease, is mediated by an actomyosin motor anchored in the outer pellicle of the motile cell. Effective motility is dependent on a parasite myosin motor and turnover of dynamic parasite actin filaments. To date, however, the basis for directional motility is not known. Whilst myosin is very likely orientated as a result of its anchorage within the parasite, how actin filaments are orientated to facilitate directional force generation remains unexplained. In addition, recent evidence has questioned the linkage between actin filaments and secreted surface antigens leaving the way by which motor force is transmitted to the extracellular milieu unknown. Malaria parasites possess a markedly reduced repertoire of actin regulators, among which few are predicted to interact with filamentous (F)-actin directly. One of these, PF3D7_1251200, shows strong homology to the coronin family of actin-filament binding proteins, herein referred to as PfCoronin.

Methods: Here the $\mathrm{N}$ terminal beta propeller domain of PfCoronin (PfCor- $\mathrm{N}$ ) was expressed to assess its ability to bind and bundle pre-formed actin filaments by sedimentation assay, total internal reflection fluorescence (TIRF) microscopy and confocal imaging as well as to explore its ability to bind phospholipids. In parallel a tagged PfCoronin line in Plasmodium falciparum was generated to determine the cellular localization of the protein during asexual parasite development and blood-stage merozoite invasion.

Results: A combination of biochemical approaches demonstrated that the $\mathrm{N}$-terminal beta-propeller domain of PfCoronin is capable of binding F-actin and facilitating formation of parallel filament bundles. In parasites, PfCoronin is expressed late in the asexual lifecycle and localizes to the pellicle region of invasive merozoites before and during erythrocyte entry. PfCoronin also associates strongly with membranes within the cell, likely mediated by interactions with phosphatidylinositol-4,5-bisphosphate $\left(\mathrm{PI}(4,5) \mathrm{P}_{2}\right)$ at the plasma membrane.

Conclusions: These data suggest PfCoronin may fulfil a key role as the critical determinant of actin filament organization in the Plasmodium cell. This raises the possibility that macro-molecular organization of actin mediates directional motility in gliding parasites.
\end{abstract}

Keywords: Gliding motility, Coronin, Actin, Plasmodium, Tight junction, Merozoite

\footnotetext{
${ }^{*}$ Correspondence: jake.baum@imperial.ac.uk

${ }^{8}$ Department of Life Sciences, Imperial College London, Sir Alexander

Fleming Building, Level 6, South Kensington, London SW72AZ, UK

Full list of author information is available at the end of the article
} 


\section{Background}

The infectious stages of Plasmodium parasites, the etiological agents of malaria, are exquisitely designed for cell motility and targeted host cell invasion. Despite traversing several very different tissue environments and invading divergent host cells in the mosquito and vertebrate hosts $[1,2]$, each life cycle stage retains a conserved cellular architecture [3, 4] and mode of actomyosin-based cell movement, called gliding motility. The mechanics of gliding is intimately linked to the cellular architecture of the apicomplexan cell, the phylum to which malaria parasites belong [4]. The pellicular region underlying the plasma membrane houses much of the machinery associated with motility. Comprised of a series of membrane bound structures, termed the inner membrane complex or IMC, this compartment lies some $20-50 \mathrm{~nm}$ under the plasma membrane [4], the space between housing the gliding motor complex. Current models predict that this structure is composed of a single headed myosin motor, anchored between the IMC and plasma membrane via a series of binding partners [5]. Motor action then provides the requisite force necessary for motility [6]. Myosin engages directly with transient, short actin filaments that are themselves linked to the extracellular milieu via the cytoplasmic tails of surface bound adhesins [7]. Until recently, the linkage between actin filaments and the terminal residues of surface-bound adhesins was thought to involve the glycolytic enzyme fructose 1,6 bisphosphate aldolase [7], which is known to bind actin [8]. According to this model, directional passage of the actin-aldolase-adhesin complex rearwards by the myosin motor would then generate rearward force driving the parasite forwards.

Whilst the current model for gliding is appealing it does not explain how directional motility is generated. To date, efforts to visualize motor organization or actin in the pellicle of the parasite have not been successful $[9,10]$. Recent evidence from the apicomplexan parasite Toxoplasma gondii, a distant relative of Plasmodium parasites, has also brought into question not only the role of aldolase, beyond its metabolic contribution [11], but also the essential contribution of each motor complex component to motility in general [12]. Thus, the question of how directional force generation and subsequent directional gliding is achieved remains entirely unresolved.

Drugs that perturb microfilament turnover demonstrate the importance of dynamic actin to gliding motility $[13,14]$. Since actin forms a polar filament, proteins that interact in an orientated fashion constitute attractive candidates that might impact significantly on directional motility. Computational analysis of available apicomplexan genomes has revealed a remarkable reduction in the repertoire of identifiable actin regulators and actin-binding proteins in this phylum [15-17]. The minimal set in Plasmodium parasites includes two formins [18], a single profilin [19], two actin depolymerizing factors (ADF) [20,21], a homologue of the yeast-actin regulator srv2 or CAP protein [22, 23], capping subunits alpha and beta [24] and coronin [25]. Among this minimal repertoire of core actin regulators only coronin appears to fulfil the role of a specific filament binding protein. Coronins are a family of proteins implicated in several roles involving actin dynamics across eukaryotic systems including filament binding and bundling [26-28]. Based on sequence comparison coronins have been divided into three groups, Types I-III [26]. Type I coronins are defined by a three-part structure consisting of an $\mathrm{N}$ terminal seven bladed beta-propeller motif composed of WD40 repeats [29], a "unique" middle region that varies in sequence and length between variants and species, and a C-terminal coiled-coil (CC) domain that mediates homo-oligomerization [30] and interactions with the Arp2/3 complex [31], a key nucleation complex entirely absent in malaria parasites. Apicomplexan coronins are predicted to resemble Type I coronins, with recent structural analysis of $T$. gondii coronin (TgCoronin) revealing a conserved $\mathrm{N}$-terminal beta propeller motif and mostly conserved actin-binding residues, as well as a potential dimerization motif in the C-terminal CC domain [32].

Here the biochemical interactions of the Plasmodium falciparum coronin-like protein (PfCoronin) and actin were addressed towards dissecting its role in organizing directional actin-based motility in Plasmodium parasites. Using genetic, cellular, biochemical and single molecule approaches, we show that PfCoronin is a true actin-filament binding protein able, in vitro, to direct filamentous (F)-actin into parallel bundles. PfCoronin peak expression is centred in late schizogony, where the protein localizes to the merozoite pellicle throughout invasion consistent with a role in motility. PfCoronin interacts with membrane fractions of the parasite cell, likely binding via phosphatidylinositol 4,5-bisphosphate $\left(\mathrm{PI}(4,5) \mathrm{P}_{2}\right)$. Given its potential for organizing actin filaments in situ at the parasite periphery into parallel bundles, a model in which coronin is a key determinant of directional gliding motility in apicomplexan parasites can be proposed.

\section{Methods}

\section{Cloning, protein expression and purification}

PfCoronin: The full-length gene encoding $6 \times$ His-PfCoroninFL was codon optimized for expression in Sf21 cells (GeneArt). The synthetic gene was cloned into the pFastBacHTB vector using BamHI/XhoI restriction sites. Bacmid DNA was produced according to the Bac-toBac manual (Invitrogen) using MultiBac cells. Bacmid DNA was transfected into Sf21 cells using Cellfectin II 
(Invitrogen) according to the manufacturers instructions. Viral stocks were amplified and used at a 1:1,000 dilution for protein expression. Following addition of virus, Sf21 cells were incubated in suspension at $27^{\circ} \mathrm{C}$ and harvested by centrifugation after $72 \mathrm{~h}$. Cells were re-suspended in lysis buffer (50 mM Tris $\mathrm{pH} 8.0,300 \mathrm{mM} \mathrm{NaCl}$, $10 \mathrm{mM} \mathrm{MgCl}$, $5 \mathrm{mM}$ 2-mercaptoethanol, 0.5\% Triton $\mathrm{X}$-100) supplemented with cOmplete EDTA-free protease inhibitors (Roche) and subjected to two rounds of freeze-thaw in liquid $\mathrm{N}_{2}$. The lysate was incubated with $1 \mathrm{mg} / \mathrm{mL}$ DNAseI for $30 \mathrm{~min}$ rocking at $4^{\circ} \mathrm{C}$, followed by centrifugation at $30,000 \mathrm{~g}$ for $30 \mathrm{~min}$. The soluble fraction was recovered, adjusted to $10 \mathrm{mM}$ imidazole $\mathrm{pH} 8.0$ and incubated with Profinity ${ }^{\mathrm{TM}} \mathrm{IMAC}$ resin for $2 \mathrm{~h}$ at $4^{\circ} \mathrm{C}$. The resin was washed sequentially with buffer 1 (50 mM Tris pH 8.0, $300 \mathrm{mM} \mathrm{NaCl}, 5 \mathrm{mM}$ 2-mercaptoethanol, $20 \mathrm{mM}$ Imidazole), buffer 2 (50 mM Tris pH 8.0, $1 \mathrm{M}$ $\mathrm{NaCl}, 5 \mathrm{mM}$ 2-mercaptoethanol) and buffer 1. Protein was eluted in elution buffer (50 mM Tris pH 8.0, $300 \mathrm{mM}$ $\mathrm{NaCl}, 5 \mathrm{mM}$ 2-mercaptoethanol, $250 \mathrm{mM}$ Imidazole) and analysed by SDS PAGE. Fractions containing HisPfCoronin were pooled and cleaved overnight with TEV protease during dialysis against buffer $3(50 \mathrm{mM}$ Tris $\mathrm{pH}$ 8.0, $300 \mathrm{mM} \mathrm{NaCl}, 5 \mathrm{mM}$ 2-mercaptoethanol) to remove the $6 \times$ His tag. The dialyzed protein was incubated with Profinity ${ }^{\mathrm{TM}}$ IMAC resin for $2 \mathrm{~h}$ to bind un-cleaved protein. The cleaved protein was collected and the resin washed with buffer 3 until no more protein came off as monitored by Bradford reagent (BioRad). The cleaved sample and washes were pooled and concentrated to $0.5 \mathrm{~mL}$. The protein was subjected to size exclusion chromatography on a Superdex 200 10/300 GL column (GE Healthcare) pre equilibrated in $30 \mathrm{mM}$ Tris $\mathrm{pH} 8.0,300 \mathrm{mM} \mathrm{NaCl}$, 5 mM 2-mercaptoethanol. Full length PfCoronin eluted at $\sim 12 \mathrm{~mL}$. The N-terminal breakdown product PfCoronin 1-388 (called herein PfCor-N), eluted at $\sim 16 \mathrm{~mL}$. Peak fractions were analysed by Coomassie-stained SDS PAGE to assess protein purity. Fractions containing PfCor- $\mathrm{N}$ were pooled, concentrated and stored at $4^{\circ} \mathrm{C}$.

PfAldolase The gene for PfAldolase was amplified from P. falciparum genomic DNA using the primers PfAldoF 5'GATCGGATCCATGGCTCATTGCACTGAATA TATG and PfAldoR 5'GATCCTCGAGTTAATAGA CATATTTCTTTTC, and ligated into the pProEX-HTb vector (Invitrogen) via BamHI/Xhol restriction sites, introducing an $\mathrm{N}$-terminal $6 \times \mathrm{His}$ tag. The plasmid was transformed into BL21 (DE3) Escherichia coli cells and the protein expressed for $4 \mathrm{~h}$ at $37^{\circ} \mathrm{C}$ after addition of $1 \mathrm{mM}$ IPTG. The cells were harvested, re-suspended in lysis buffer (20 mM Tris pH 8.0, $300 \mathrm{mM} \mathrm{NaCl}, 0.3 \%$ Triton X-100, $5 \mathrm{mM}$ 2-mercaptoethanol) supplemented with cOmplete EDTA-free protease inhibitors. The suspension was sonicated and clarified by centrifugation at
$30,000 \mathrm{~g}$ for $30 \mathrm{~min}$ at $4^{\circ} \mathrm{C}$. The supernatant was collected, adjusted to $10 \mathrm{mM}$ imidazole $\mathrm{pH} 8.0$ and incubated for $2 \mathrm{~h}$ at $4^{\circ} \mathrm{C}$ with Profinity ${ }^{\mathrm{TM}}$ IMAC resin. The resin was washed sequentially with Wash Buffer 1 (50 mM Tris pH 8.0, $300 \mathrm{mM} \mathrm{NaCl}, 20 \mathrm{mM}$ imidazole $\mathrm{pH}$ 8.0, $5 \mathrm{mM}$ 2-mercaptoethanol), Wash buffer 2 (50 mM Tris pH 8.0, $1 \mathrm{M} \mathrm{NaCl}, 5 \mathrm{mM}$ 2-mercaptoethanol) and Wash Buffer 3 (50 mM Tris pH 8.0, $300 \mathrm{mM} \mathrm{NaCl}, 5 \mathrm{mM}$ 2-mercaptoethanol). His-PfAldolase was eluted with elution buffer (Wash Buffer $3+250 \mathrm{mM}$ imidazole $\mathrm{pH}$ 8.0) and assessed for purity and quantity by SDS PAGE. Elution fractions containing His-PfAldolase were pooled and dialysed against Buffer A (50 mM MES pH 7.0, $100 \mathrm{mM}$ $\mathrm{NaCl}, 2 \mathrm{mM}$ DTT, $1 \mathrm{mM}$ EDTA) for $2 \mathrm{~h}$, then subjected to cation exchange chromatography using HiTrap SPFF (GE Healthcare). A gradient from buffer A to buffer B (50 mM MES pH 7.0, $1 \mathrm{M} \mathrm{NaCl}, 2 \mathrm{mM}$ DTT, $1 \mathrm{mM}$ EDTA) was used to elute the protein. Peak fractions containing HisPfAldolase, as determined by Coomassie-stained SDS PAGE, were pooled, concentrated and subjected to size exclusion chromatography using a Superdex 200 10/300 gel filtration column (GE Healthcare) pre-equilibrated in Buffer A. His-PfAldolase eluted off the column as a single peak at $\sim 13 \mathrm{~mL}$, corresponding to a molecular weight of $\sim 160 \mathrm{kDa}$ which approximates the size of a tetramer. Peak fractions were pooled, concentrated to $100 \mathrm{uM}$, aliquoted, flash frozen in liquid $\mathrm{N}_{2}$ and stored at $-80^{\circ} \mathrm{C}$. Actin was purified from rabbit skeletal muscle acetone powder (Sigma-Aldrich) using established protocols [33].

\section{Sedimentation assays}

High speed $2 \mu \mathrm{M}$ RSMA in CaBG was adjusted by the addition of $10 \times \mathrm{Mg}$-EGTA exchange buffer (ME) (10 mM MgCl, 2 mM EGTA) to make Mg bound RSMA (Mg-ATP-Actin). Mg-ATP-Actin was polymerized by the addition of $10 \times \mathrm{KMEI}(0.5 \mathrm{M} \mathrm{KCl}, 0.1 \mathrm{M}$ imidazole $\mathrm{pH}$ 7.0, 0.01 EGTA pH 8.0, 0.01 $\mathrm{M} \mathrm{MgCl}_{2}$ ) and incubation for $2 \mathrm{~h}$ at room temperature. Proteins of interest [PfCor-N, PfAldolase and alpha-Actinin (Cytoskeleton Inc.)] were added to the appropriate concentration and the mixture incubated for a further $30 \mathrm{~min}$ at room temperature. The samples were centrifuged at 60,000 rpm in a Beckman preparative ultracentrifuge for $1 \mathrm{~h}$ at room temperature. The supernatant was carefully removed and adjusted with $5 \times$ RSB. The pellet was rinsed with MgBG ( $2 \mathrm{mM}$ Tris $\mathrm{pH}$ 8.0, 0.2 mM ATP, 0.5 mM DTT, 0.1 $\mathrm{mM} \mathrm{MgCl}_{2}$ ) and centrifuged at $60,000 \mathrm{rpm}$ in a Beckman preparative ultracentrifuge for $1 \mathrm{~h}$ at room temperature. The supernatant was carefully removed and discarded, and the pellet re-suspended in $2 \times$ RSB to a volume equivalent to the first supernatant after addition of RSB. The supernatant and pellet samples were boiled for $5 \mathrm{~min}$ and equal volumes were separated by SDS PAGE, the gels stained with 
Coomassie brilliant blue (BioRad) and the bands analysed by densitometry.

Low speed Low-speed sedimentation assays were performed as per high-speed sedimentation assays with the following alterations. Mg-ATP-Actin was polymerized in the presence of the proteins of interest for $2 \mathrm{~h}$ at room temperature. Samples were centrifuged at 13,000 rpm in a standard benchtop centrifuge at $4^{\circ} \mathrm{C}$. Supernatants were carefully collected and the pellet discarded. Supernatants were adjusted with $5 \times \mathrm{RSB}$, boiled for $5 \mathrm{~min}$ and separated by SDS PAGE. The gels were stained with Coomassie brilliant blue and the bands analysed by densitometry.

$K d$ determination Pre-polymerized Mg-ATP-Actin, prepared as per the high-speed sedimentation assay protocol, was incubated with the protein of interest for $30 \mathrm{~min}$ then centrifuged at $60,000 \mathrm{rpm}$ for $1 \mathrm{~h}$ at $22^{\circ} \mathrm{C}$. The supernatants were collected, and adjusted with $5 \times$ RSB. The pellets were rinsed with $1 \times \mathrm{KMEI}$ and centrifuged as per the high-speed sedimentation assay protocol. The pellets were re-suspended in $2 \times \mathrm{RSB}$ to the equivalent volume of the supernatant samples. Equal volumes were separated by SDS PAGE and the gels stained with Coomassie brilliant blue. For assays involving proteins too close in size to resolve by standard Coomassie staining, following SDS PAGE the proteins were subjected to Western blot analysis. Band densities were analysed by densitometry and $K d \mathrm{~s}$ determined according to the methods outlined in $[34,35]$.

\section{Electron microscopy}

Appropriate amounts of purified PfCor-N or PfAldolase were added to $2 \mu \mathrm{M}$ preformed Mg-ATP-Actin filaments for $30 \mathrm{~min}$ at room temperature. The samples were adsorbed onto Formvar-carbon films supported on 200mesh copper grids. Grids were glow discharged before sample application, then negatively stained with aqueous uranyl acetate (1\%). Samples were observed with an FEI Tecnai F30 microscope at $300 \mathrm{kV}$.

\section{Fluorescence microscopy}

Mg-ATP-Actin was polymerized by the addition of $2 \times$ TIRF buffer alone or in the presence of proteins of interest and incubated in a covered tube at room temperature for $1 \mathrm{~h}$. The samples were incubated with $1 \mu \mathrm{M}$ Alexa Fluor ${ }^{\circledR} 488$ Phalloidin (Life Technologies) for $5 \mathrm{~min}$ at room temperature. $3 \mu \mathrm{L}$ of the samples were adsorbed onto coverslips coated with $0.05 \mu \mathrm{g} / \mu \mathrm{L}$ poly-L-Lysine (Sigma-Aldrich). Fluorescence images were acquired using a Zeiss inverted LSM-510 confocal microscope and processed using ICY image analysis software [36].

\section{TIRF microscopy}

Oregon Green (OG) labelled RSMA was prepared as previously described [37]. $1.5 \mu \mathrm{M} \mathrm{Mg-ATP-Actin} \mathrm{(33 \%} \mathrm{OG}$ labeled) alone and in the presence of proteins of interest (Pf-Cor or Fimbrin, a kind gift from Colleen T. Skau) was prepared for TIRF microscopy by the addition of $2 \times$ TIRF buffer (10 mM imidazole $\mathrm{pH} 7.0,50 \mathrm{mM} \mathrm{KCl}, 5 \mathrm{mM}$ $\mathrm{MgCl}_{2}, 1 \mathrm{mM}$ EGTA, $0.5 \mathrm{mM}$ DTT, $0.2 \mathrm{mM}$ ATP, $50 \mu \mathrm{M}$ $\mathrm{CaCl} 2,15 \mathrm{mM}$ glucose, $20 \mu \mathrm{g} / \mathrm{mL}$ catalase, $100 \mu \mathrm{g} / \mathrm{mL}$ glucose oxidase, $0.5 \%$ methylcellulose $400 \mathrm{cP}$ ) to stimulate polymerization. The samples were immediately loaded into a pre-made flow chamber and excited by evanescent wave fluorescence on an IX-71 Olympus microscope fit with through the objective TIRF illumination. Images were acquired every $15 \mathrm{~s}$ for $10-20 \mathrm{~min}$ by an iXon EMCCD camera (Andor Technology) as previously described [38]. Movies were processed and analysed using ImageJ.

\section{Plasmodium falciparum culture and maintenance}

The 3D7 P. falciparum isolate was cultured as previously described [39]. Parasites were maintained in $\mathrm{O}^{+}$ erythrocytes (Australian Red Cross Blood Bank, South Melbourne, Australia) at approximately 4\% haematocrit, in a culture medium of RPMI-HEPES supplemented with $0.18 \%(\mathrm{w} / \mathrm{v}) \mathrm{NaHCO} 3$ and $10 \%(\mathrm{v} / \mathrm{v})$ pooled human serum from unexposed Melbourne blood donors or $0.5 \%$ (w/v) AlbumaxII (Gibco). Cultures were incubated at $37^{\circ} \mathrm{C}$ under a $94 \% \mathrm{~N}_{2}, 1 \% \mathrm{O}_{2}, 5 \% \mathrm{CO}_{2}$ gas environment. Transfected lines were maintained in the presence of appropriate drugs to select for the corresponding resistance marker included in the transfection vectors.

\section{Reverse transcriptase PCR (RT-PCR)}

RT-PCR was performed as described [40]. Briefly, total RNA was extracted from synchronized 3D7 parasites at appropriate time points post-invasion using TRIzol ${ }^{\circledR}$ (Invitrogen), residual genomic DNA was removed using an RNAeasy ${ }^{\circledR}$ column (Qiagen), and $5 \mu \mathrm{g}$ of total RNA was reverse transcribed with or without SuperScript ${ }^{\mathrm{TM}}$ II reverse transcriptase using random hexamers (Invitrogen), all according to the manufacturers instructions. The following primers were used: Cor_RT_fwd (5'-CCTT TAATCAAGAATTTATA-TCC-3') and Cor_RT_rev (5'-C CTCATTCACATTCTCATCCTC-3'); ACT1_RT_fwd (5'-C CAAAGAATCCAGGAATTATGG-3') and ACT1_RT_rev (5'-GGAACAGTGTGTGATA-CACCATC-3').

\section{Vector construction and tagging}

Endogenous tagging of PfCoronin (PF3D7_1251200) at the $\mathrm{C}$-terminus was performed as described using the pD3HA vector with parasite transfection following standard protocols [41].

\section{Antisera and immunoprecipitation}

Antisera was raised in rabbits against PfCor-N, expressed and purified from BL21 (DE3) E. coli using standard 
methods. Immunoprecipitation was performed as previously described [40]. Briefly, 40-48 h 3D7 PfCoroninHA schizonts were subjected to protein extraction using $1 \%$ TNET (1\% Triton X-100, $50 \mathrm{mM}$ Tris $\mathrm{pH}$ 7.4, $150 \mathrm{mM} \mathrm{NaCl}, 5 \mathrm{mM}$ EDTA) supplemented with cOmplete EDTA-free protease inhibitor cocktail (Roche). Pull downs were performed using anti-PfCoronin or anti-HA coupled to protein G-Sepharose (Amersham Biosciences) according to the manufacturers instructions. Proteins were separated by SDS PAGE and subjected to western blot analysis. The blots were probed with rat anti-HA $[1: 1,000]$ or rabbit anti-PfCoronin [1:1,000] and processed as previously described.

\section{Immunofluorescence assays}

Parasites were synchronized according to established methods to obtain late schizonts or merozoites for reinvasion using either sorbitol or heparin treatment [42, 43]. Schizonts or invading parasites were fixed in a fixing solution of $4 \%$ paraformaldehyde (ProSciTech) $/ 0.0075 \%$ gluteraldehyde (ProSciTech) in phosphate buffered saline (PBS) while rocking at room temperature for $30 \mathrm{~min}$. Cells were permeabilized using $0.1 \%$ Triton X-100 (Bio$\mathrm{Rad}$ ) for $10 \mathrm{~min}$ at room temperature and blocked overnight using Blocking Solution [3\% (w/v) Bovine Serum Albumin (BSA) (Sigma-Aldrich) in PBS], while rocking at $4^{\circ} \mathrm{C}$. Cells were incubated with appropriate primary antibodies diluted in Blocking Solution for $1 \mathrm{~h}$ at $4^{\circ} \mathrm{C}$. Primary antibodies used were rat anti-HA [1:1,000] (Roche), rabbit anti-PfGAP45 [1:500] [40], rabbit anti-Act 239-253 [1:300] [10], mouse anti-PfRON4 [1:500] [44]. Samples were washed twice in PBS and incubated for $1 \mathrm{~h}$ at $4^{\circ} \mathrm{C}$ with appropriate secondary antibodies: Alexa Fluor ${ }^{\circledR} 488$ or 594 goat anti-mouse, Alexa Fluor ${ }^{\circledR} 488$ or 594 goat anti-rabbit and Alexa Fluor ${ }^{\circledR} 594$ goat anti-rat (Invitrogen) [1:500] in Blocking Solution. Samples were washed three times in PBS and cells were settled onto coverslips (type 1.5, Zeiss) coated with $1 \%$ polyethyleneimine (PEI) (Sigma-Aldrich). Cells were mounted with VectaShield ${ }^{\circledR}$ (Vector Laboratories) with $0.1 \mathrm{ng} / \mu \mathrm{L}$ 4',6-diamidino2-phenylindole (DAPI) (Invitrogen). Fluorescence images were acquired using Plan-Apochromat $100 \times / 1.40$ oil immersion Phase contrast lens (Zeiss) on an AxioVert $200 \mathrm{M}$ microscope (Zeiss) equipped with an AxioCam Mrm camera (Zeiss). Deconvolution of image stacks was undertaken using Axiovision release 4.7 or 4.8 software. Routine image manipulation was performed using FIJI and Adobe Photoshop.

\section{Solubility profile analysis}

For solubility analysis of PfCoronin purified 3D7 P. falciparum merozoites were hypotonically lysed by resuspending the merozoites in water supplemented with complete EDTA-free protease inhibitor cocktail (Roche). The samples were snap frozen in liquid $\mathrm{N}_{2}$ and incubated on ice for $10 \mathrm{~min}$ to thaw, releasing the cell contents. Water soluble and insoluble proteins were separated by ultracentrifugation at $1,00,000 \mathrm{~g}$ for $30 \mathrm{~min}$ at $4^{\circ} \mathrm{C}$ (TLA100.2 rotor, Beckman Optima TL Ultracentrifuge, Beckman Coulter). Water insoluble fractions were further treated with $\mathrm{Na}_{2} \mathrm{CO}_{3} \mathrm{pH} 11.5$ for $1 \mathrm{~h}$ at $4^{\circ} \mathrm{C}$. Carbonate soluble and insoluble fractions were isolated by ultracentrifugation as described. Samples were adjusted with $4 \mathrm{x}$ reducing sample buffer (RSB) and subject to sodium dodecyl sulfate polyacrylamide gel electrophoresis (SDS PAGE) followed by Western blot analysis.

\section{Biosensor analysis}

The amino analogue of $\mathrm{PI}(4,5) \mathrm{P} 2$ (NH2-PI(4,5)P2 was synthesized with an $\omega$-amino group on the sn-1 position of a saturated lipid side chain as described previously [45]. NH2-PI(4,5)P2 was then conjugated with Sulfo-NHS-biotin (Thermo Scientific) to enable immobilization onto the NeutrAvidin derivatized sensor surface according to a previously described protocol [46]. Experiments were performed using a Biacore 3000 biosensor (Biacore Life Sciences, GE Healthcare). Various concentrations of PfCor-N (2.6 $\mu \mathrm{M}, 1.3 \mu \mathrm{M}, 650 \mathrm{nM}, 325 \mathrm{nM}$, $162.5 \mathrm{nM}$ and $81.2 \mathrm{nM})$ and PfADF1 $(3.8 \mu \mathrm{M}, 1.9 \mu \mathrm{M}$, $950 \mathrm{nM}, 475 \mathrm{nM}, 237.5 \mathrm{nM}$, and $188.8 \mathrm{nM}$ ) were injected over PI(4.5)P2, immobilized onto a CM5 sensor surface derivatized with NeutrAvidin using NHS/EDC chemistry (140RU immobilized) (Catimel 2013). A NeutrAvidin channel was used as the control. The reactivity of immobilized PI(4,5)P2 was assessed by injecting various concentrations of the GST-tagged Pleckstrin Homology domain of Phospholipase C, gamma 1 (GST-PLC $\delta$-PH) (350, 175, 87.5, 43.8, 21.9 and $11 \mathrm{nM})$ [46].

Kinetic constants were derived from the resulting sensorgrams with BIAevaluation 4.1 software (Biacore Life Sciences, GE Healthcare) using Global analysis using a 1:1 Langmuir model that includes terms for mass transfer of analyte to the surface.

\section{Results}

\section{Full length PfCoronin is unstable}

To begin to explore the contribution of P. falciparum coronin (PfCoronin) to gliding motility, an N-terminally $6 \times$ His tagged PfCoronin was expressed and purified using a baculovirus expression system (Figure 1). Purification was performed according to an established method [29], consisting of immobilized metal affinity chromatography (IMAC), TEV cleavage to remove the His-tag and size exclusion chromatography. Throughout the purification process full-length PfCoronin $(\sim 69 \mathrm{kDa})$ rapidly degraded into a stable breakdown product of 


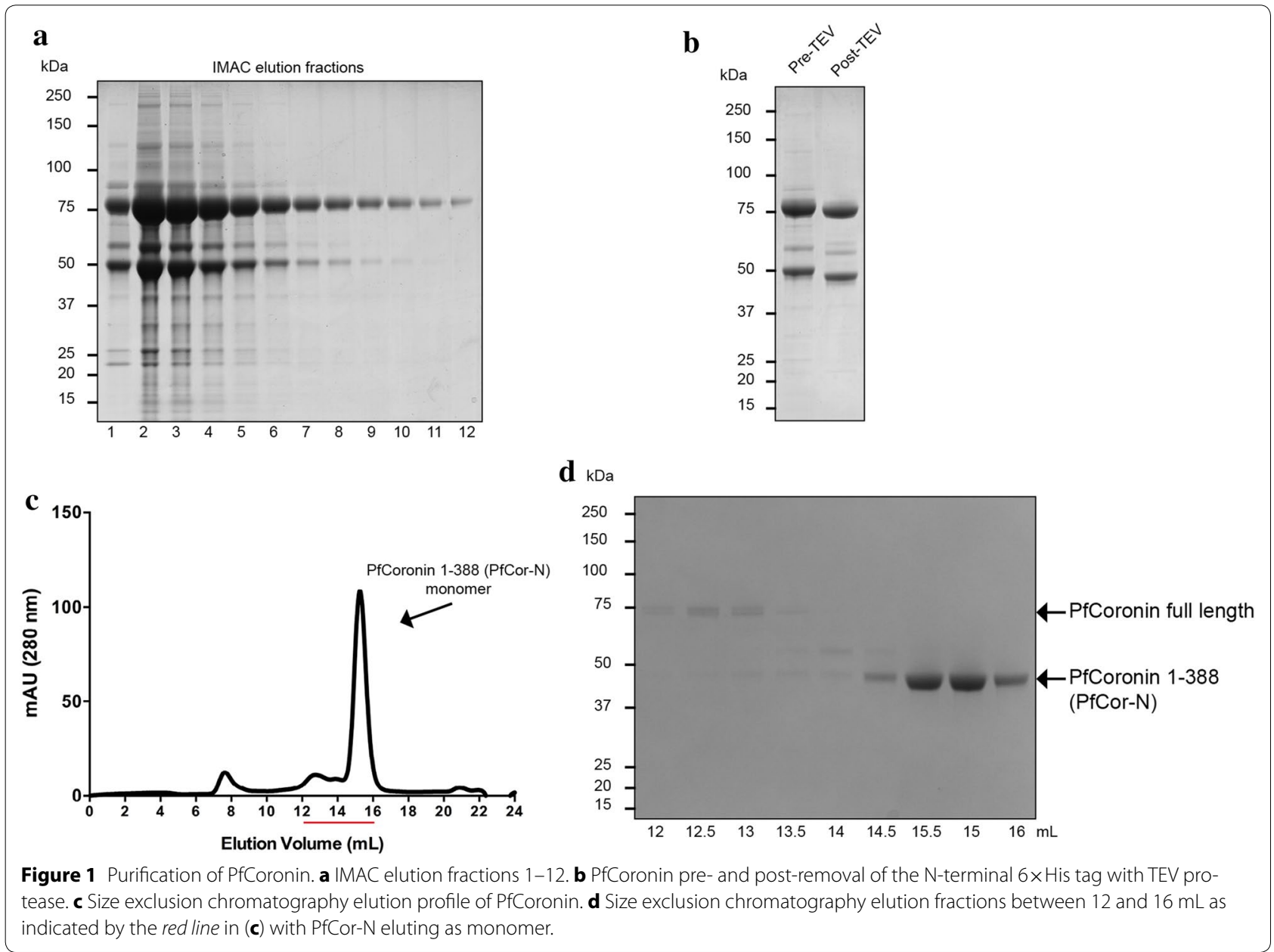

$\sim 45 \mathrm{kDa}$ (Figure 1). This was identified by mass spectrometry as the N-terminal portion of PfCoronin (amino acids 1-388) and agrees with the findings of others who observed a similar instability of purified murine coronin, which degraded from full length into a stable N-terminal breakdown product consisting of a seven bladed $\beta$-propeller domain [29]. Size exclusion chromatography demonstrated that PfCoronin (1-388), referred herein as PfCor-N, exists as a monomer in solution (Figure 1c). The degradation of predicted $\mathrm{C}$ terminal dimerization motifs precludes assessment of full length PfCoronin's ability to form multimeric complexes. Structural modelling demonstrates a likely conservation of the N-terminal $\beta$-propeller structure with that in the murine and $T$. gondii coronin structures [29, 32], suggesting structural and functional conservation (Figure 2). Sequence comparison with the Salamun et al. structure revealed only minor divergences in the potential actin binding residues between Apicomplexan coronins and those in yeast Crn1 [32], hinting towards evolutionary conservation in the interaction between Apicomplexan coronins and their actins. Given the instability of the full length PfCoronin, all biochemical analyses were performed using the stable breakdown product, PfCor- $\mathrm{N}$, containing the $\beta$-propeller domain, which contains the predicted conserved actinbinding regions.

\section{PfCor-N binds to F-actin}

To investigate the interaction between PfCor- $\mathrm{N}$ and F-actin, sedimentation assays using purified rabbit skeletal muscle actin (RSMA) were preformed (Figure 3). PfAldolase was used as a positive control as a known F-actin binding protein [47]. The similarity in size between PfAldolase and actin required the use of western blots to differentiate specifically between these proteins (Figure 3ai). Both PfCor-N and PfAldolase copelleted with $\mathrm{F}$-actin in a concentration dependant manner, indicating that each is able to efficiently bind F-actin (Figure 3a). To determine the affinity of the PfCor-N-Factin interaction, an established supernatant depletion method was utilized [34]. PfCor-N binds F-actin with a $K d=0.96 \mu \mathrm{M}$, a value between the range of $K d$ 's found 

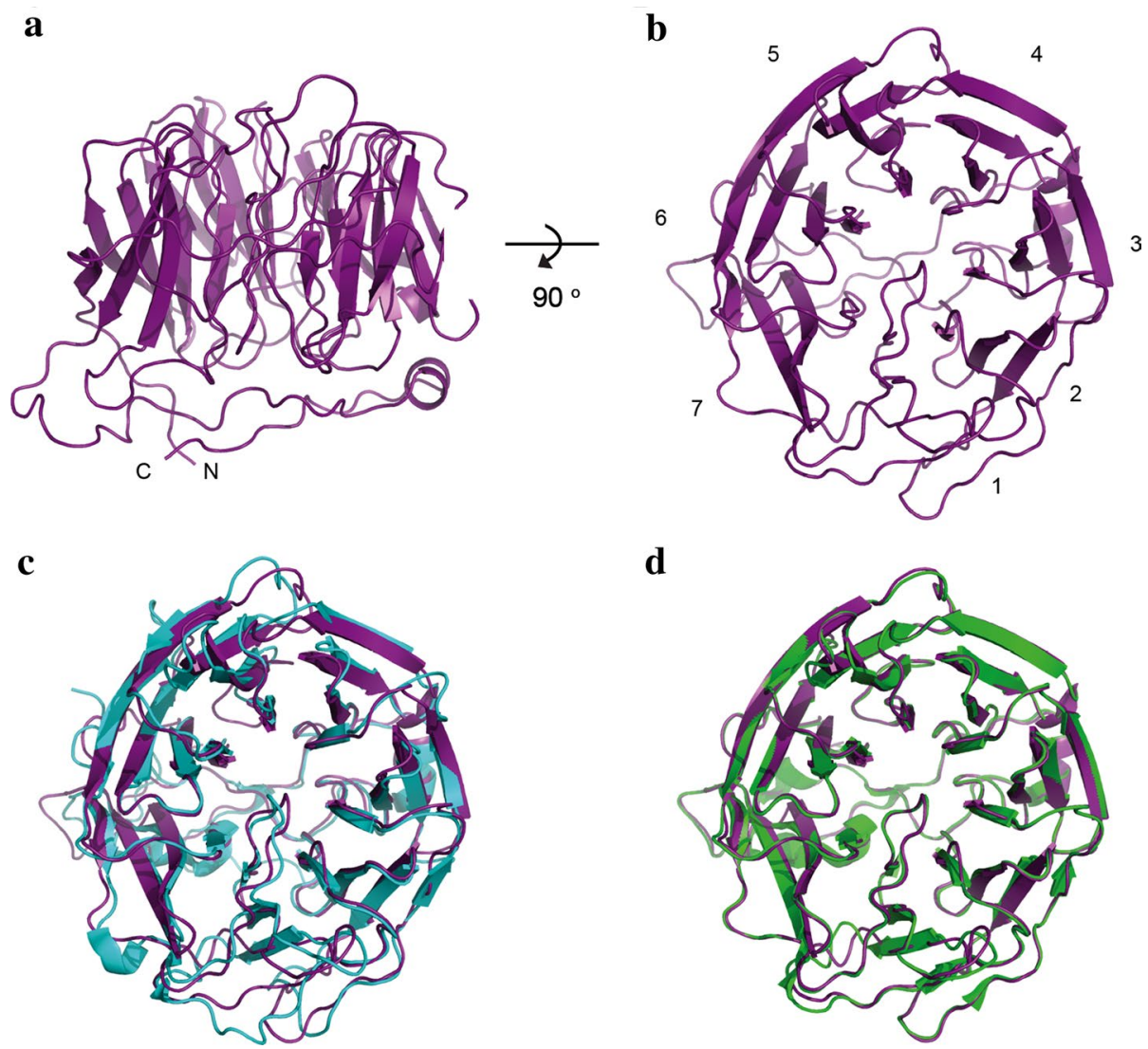

Figure 2 Homology model of PfCoronin. a Side view of homology model for PfCoronin generated using the I-TASSER server. b Top view of model. Potential blades within the propeller numbered 1-7 as per MmCoro1 A and TgCoronin. c Alignment of PfCoronin homology model (purple) with MmCoro1A structure (2AQ5.pdb, [29]) (b/ue). d Alignment of PfCoronin homology model (purple) with TgCoronin structure (4OZU.pdb, [32]) (green).

among other type I coronins such as human variants Coronin $1 \mathrm{~A}-1 \mathrm{C}(1 \mathrm{~A}, 2.57 \mu \mathrm{M} ; 1 \mathrm{~B}, 0.47 \mu \mathrm{M}$; and $1 \mathrm{C} 0.26 \mu \mathrm{M})$ [48] (Figure 3b). PfAldolase has been previously reported to bind F-actin with a $K d=0.37 \mu \mathrm{M}$ [47]. These results confirm PfCor-N as a verified F-actin binding protein.

\section{PfCor-N bundles F-actin into parallel bundles}

Low speed sedimentation assays were used as a preliminary measure of F-actin bundling, where bundles being larger than individual actin filaments are able to sediment at lower speeds $[49,50]$. Depletion of actin from the supernatant was, therefore, used as a measure of for bundling capability (Figure 3c). PfCor-N successfully depleted actin from the supernatant in a concentration dependant manner, indicating an ability to bundle F-actin (Figure 3ci). As positive control, $\alpha$-actinin, a well-characterized F-actin crosslinking/ bundling protein [51, 52] was also analysed, showing highly effective bundling at sub-micromolar concentrations (Figure 3ciii). PfAldolase, however, did not cause bundling even at the highest concentration tested
(Figure 3cii), in contrast to reports of other species of aldolase bundling F-actin [8].

To ensure that the results of the sedimentation analysis were the result of bundling and not protein aggregation samples were visualized by Transmission Electron Microscopy (TEM) to distinguish the formation of true filament bundles (Figure 4a, b). In the absence of PfCor$\mathrm{N}$, actin filaments were randomly settled across the field of view (Figure 4a). In contrast, filament bundles were observed in the presence of PfCor- $\mathrm{N}$ (Figure 4b). This is particularly noteworthy since, in other coronins, actin filament bundling has only been seen when the C-terminal oligomerization motifs are present $[32,53,54]$.

Due to limitations of negative-stain TEM for imaging large, dense structures, a lower resolution confocal imaging approach using phalloidin-labelled F-actin was used to visualize higher order F-actin networks formed in the presence of the bundling/crosslinking proteins (Figure $4 \mathrm{c}-\mathrm{f}$ ). As expected, single actin filaments were visualized in the absence of bundling/crosslinking proteins (Figure $4 \mathrm{c}$ ). In the presence of $\alpha$-actinin, large 


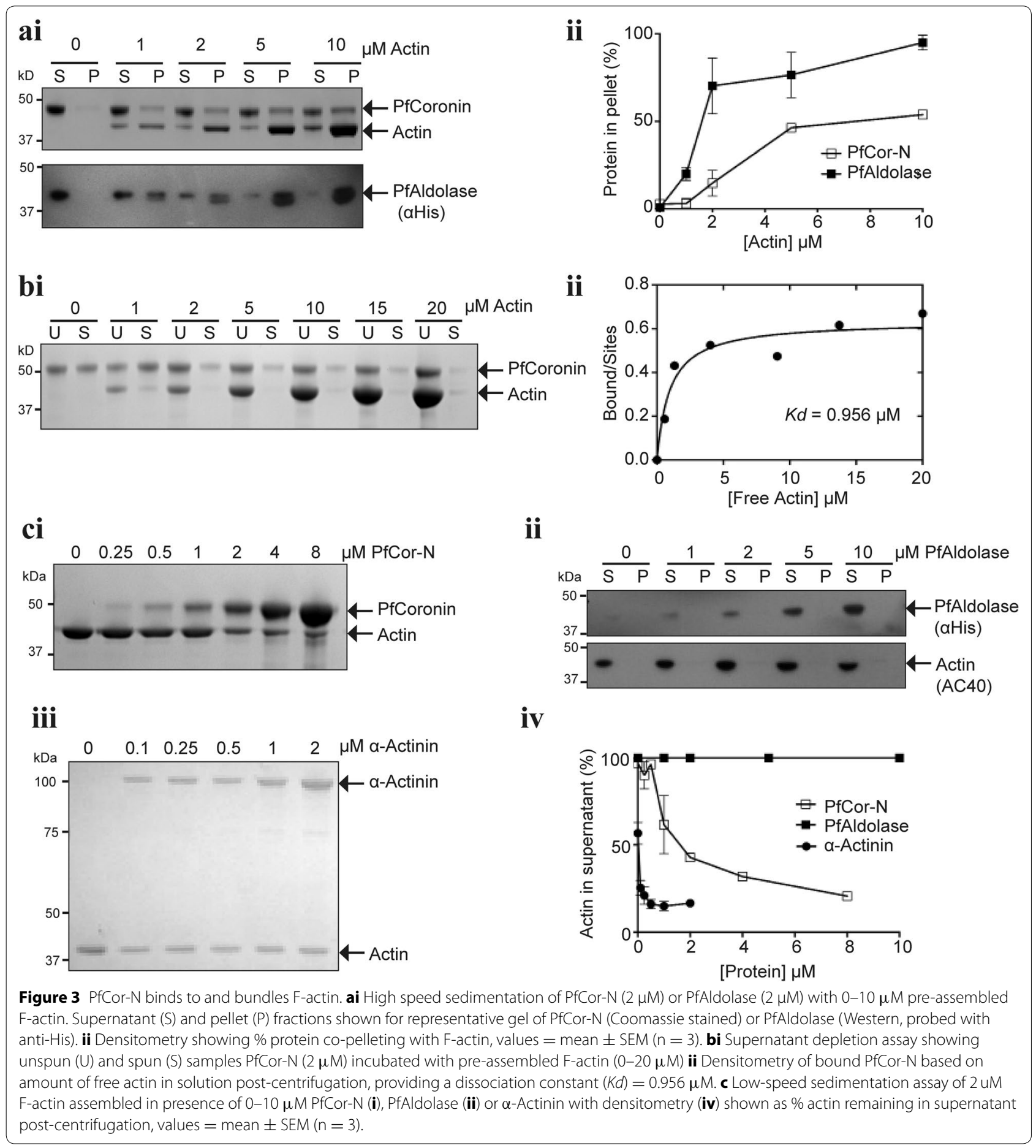

networks of crosslinked F-actin appeared, similar in structure to previous reports (Figure $4 d$ ) $[52,55]$. In the presence of PfCor- $\mathrm{N}$ however, two different structures emerged: extensive sheets of evenly distributed actin filaments and organized rows of cable-like structures (Figure $4 \mathrm{e}, \mathrm{f}$ ).
Actin filaments are polarized, with elongation occurring predominantly at the barbed end of the filament. As such, bundles can either be parallel, where the barbed ends of the filaments are aligned and growing in the same direction, or antiparallel, where barbed ends are pointed away from each other and elongation occurs in both 

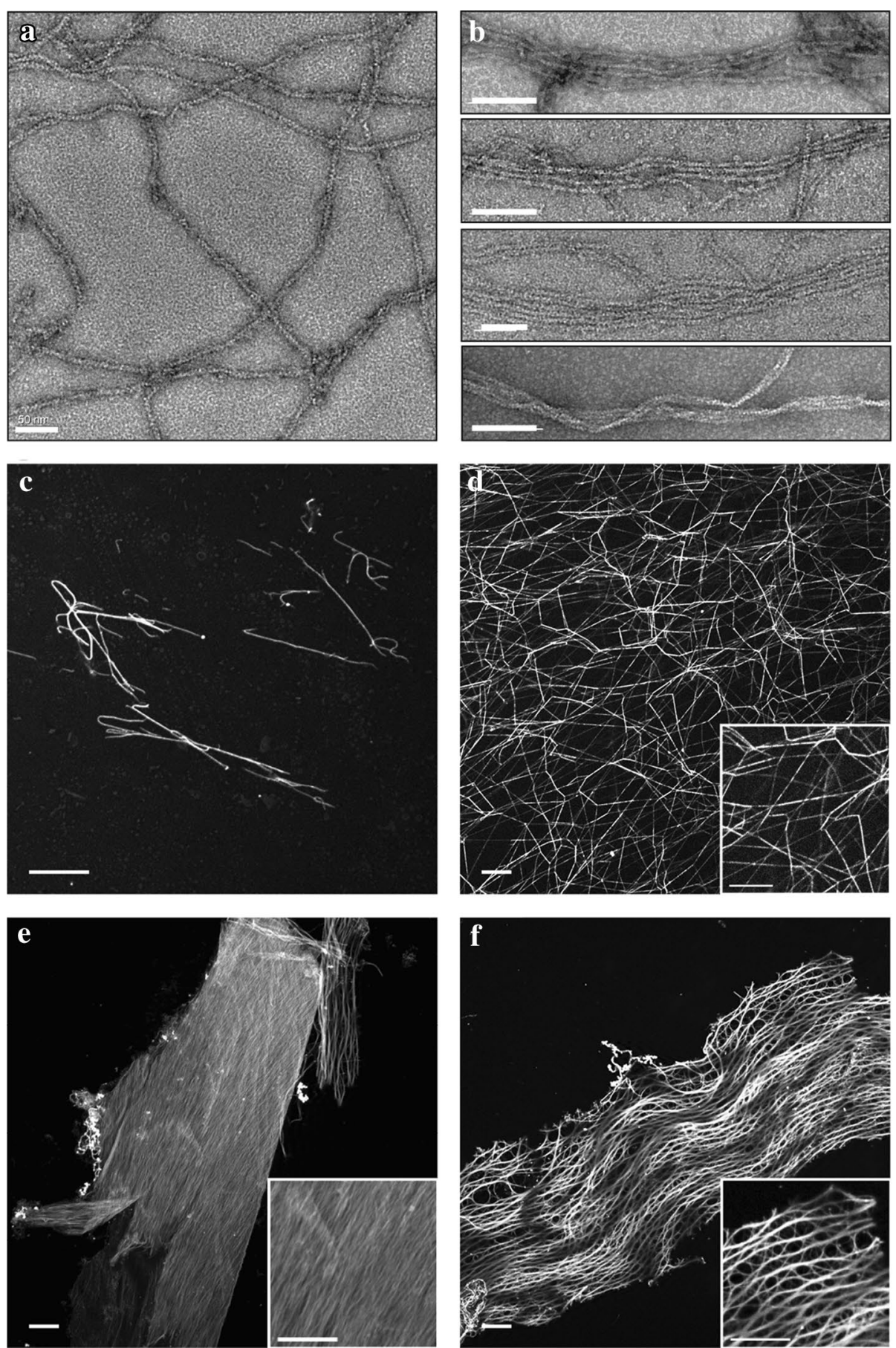

Figure 4 PfCor-N organizes F-actin into bundles and higher order sheets and networks. TEM of F-actin $(2 \mu \mathrm{M})$ alone $(\mathbf{a})$ or in presence of $0.2 \mu \mathrm{M}$ PfCor-N (b, top three panels) and $1 \mu \mathrm{M}$ PfCor-N (b, lower panel). Scale bars $50 \mathrm{~nm}(\mathbf{a}), 100 \mathrm{~nm}(\mathbf{b})$. c-f Confocal micrographs of Phalloidin-488 labelled F-actin $(1.5 \mu \mathrm{M})(\mathbf{c})$ alone, or in the presence of $\mathbf{d} 0.5 \mu \mathrm{M} \alpha$-actinin, (e-f) $0.5 \mu \mathrm{M}$ PfCor-N. Scale bars $10 \mu \mathrm{m}$.

directions along the bundle. To distinguish parallel from antiparallel bundles the formation of actin filaments was observed in real time using total internal reflection fluorescence (TIRF) microscopy of Oregon Green labelled
RSMA. In the absence of binding protein, actin filaments are seen to elongate randomly across the full field of view (Figure 5a; Additional file 1: Movie S1). In the presence of PfCor- $\mathrm{N}$ actin filaments can be seen being bundled 


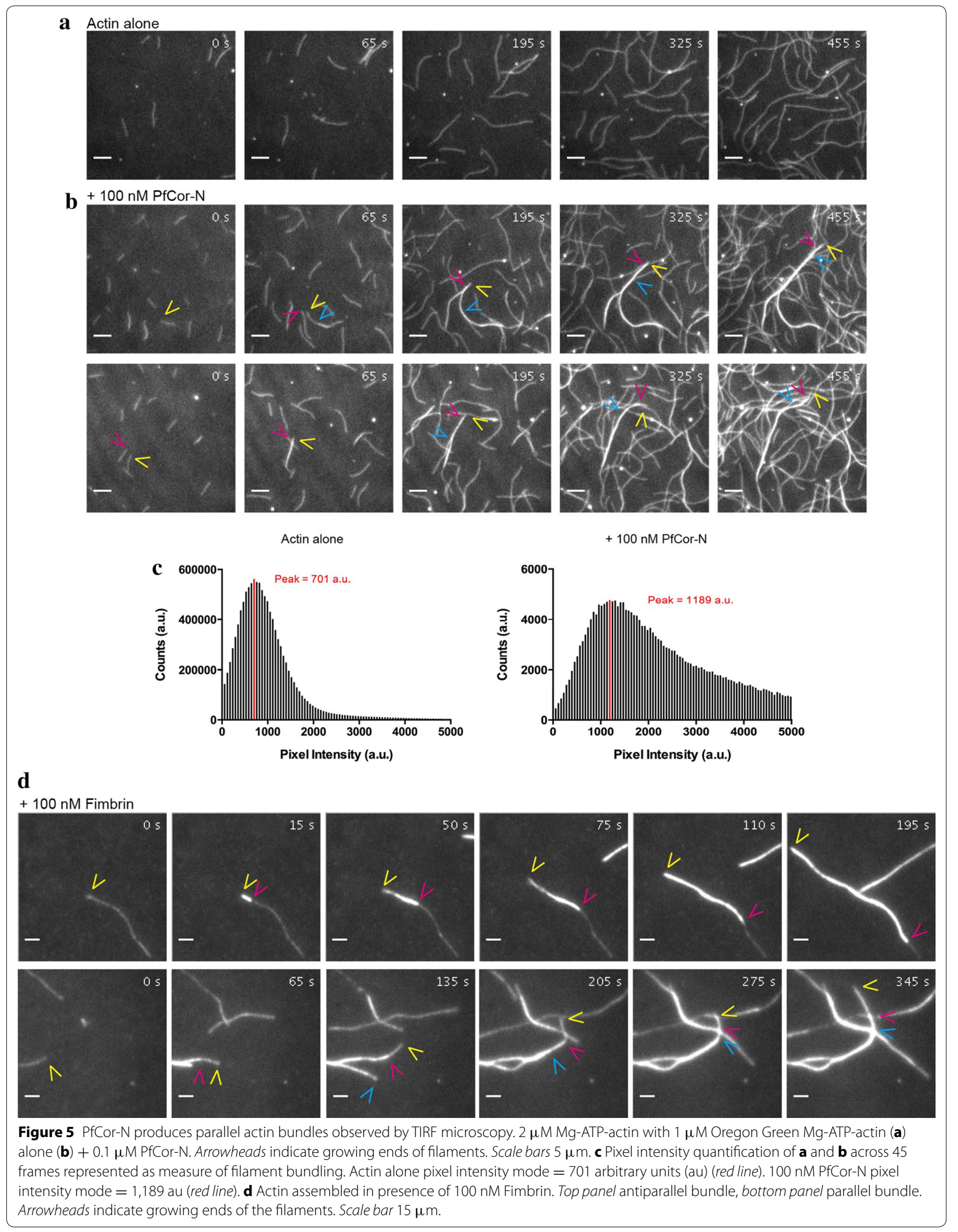


together as they elongate (Figure 5b; Additional file 2: Movie S2). Bulk analysis of pixel intensity was used as a measure of filament bundling [50, 56, 57]. Actin alone showed a Gaussian distribution of pixel intensity, while in the presence of PfCor- $\mathrm{N}$ the pixel intensity is skewed to the right (Figure 5c). This shift is again indicative of filament bundling, wherein bundles have higher pixel intensities compared with single filaments [50].

Critically, tracking of the individual microfilaments elongating into a bundle demonstrated a clear directionality. In all cases, tracking the barbed end of each filament in the presence of PfCor- $\mathrm{N}$ showed evidence for exclusively parallel forming filament bundles (Figure 5b coloured arrows; Additional file 3: Movie S3 and Additional file 4: Movie S4). For comparison the bundling protein fimbrin was used, which is known to mediate both parallel and antiparallel bundles [50]. As expected, both types of bundles were visualized in the same experiment (Figure 5d; Additional file 5: Movie S5 and Additional file 6: Movie S6). Taken together, the biochemical and microscopy data suggest that PfCor-N is capable of both binding to F-actin and organizing filaments into parallel bundles, which can then organize into large, sheet and cable like structures.

\section{PfCoronin is expressed during schizogony and localizes to the periphery of merozoites before and during invasion} Given its potential to form filamentous macroscopic structures in vitro the spatial localization of native PfCoronin was explored in P. falciparum parasites to assess its potential role in the asexual life cycle. Evaluation of mRNA transcript levels by RT-PCR revealed that the gene for PfCoronin is transcribed late in intraerythrocytic development, with a peak around $40-48 \mathrm{~h}$, corresponding to late schizonts/maturing merozoites (Figure 6a), consistent with predicted levels [58]. Of note, the size differential between genomic and mRNA PCR products conforms to the predicted presence of two introns in the native gene [59], totalling 336 base pairs, which causes a visible size shift of the band compared to a gDNA control (Figure 6a). In parallel, analysis of the PfACTI gene showed transcription levels across the asexual lifecycle.

To confirm this expression profile for the transcribed protein, a polyclonal rabbit antibody was generated against the $\mathrm{N}$-terminal portion of PfCoronin (residues 1-388, anti-PfCoronin) and validated for use in immunoblot analysis (see below). Analysis of parasite material by immunoblot probed with anti-PfCoronin confirmed a peak of protein expression late in the asexual lifecycle, in accordance with the level of the gene transcript (Figure $6 \mathrm{~b})$. The same samples were also probed with antiPfACTI (anti-Act239-253 (rabbit), [10]), anti-PfAldolase
[40] and anti-PfAMA1 [60]. PfACTI was detected across the time-course with a broad peak over the later stages of the lifecycle. PfAldolase levels were consistent with those of actin. PfAMA1, in its processed and unprocessed forms $(80 \mathrm{kDa} / 62 \mathrm{kDa}$ respectively, [61]), showed a distinct peak in late schizonts and early in invasion, consistent with its known role as an invasion ligand [62] (Figure $6 \mathrm{~b}$ ). The similarity between the expression profiles of PfCoronin and PfAMA1 is consistent with PfCoronin playing a role in blood stage merozoite invasion of the erythrocyte, a process dependent on active actomyosin motility [13].

Given a variable background in immunofluorescence microscopy assays (IFA) with anti-PfCoronin due to background non-specific labelling, endogenous tagging of the native coronin gene (PF3D7_1251200) with a C-terminal $3 \times$ haemagglutinin (HA) tag was attempted. Expression of PfCoroninHA was confirmed by Western blot of schizont lysate probed with anti-HA (Figure 6c), revealing a dominant band running above the $75 \mathrm{kDa}$ marker absent in WT controls. This is moderately higher than the predicted molecular weight of PfCoroninHA $(\sim 72 \mathrm{kDa})$, but could be indicative of membrane interactions or net negative charge that may effect protein migration through SDS. As validation, immunoprecipitation of tagged PfCoronin from late-stage schizont was performed using both anti-PfCoronin and anti-HA, with probing using the reciprocal antibody (Figure 6d). In both combinations the same band above $75 \mathrm{kDa}$ was found, which was absent in pre-immune serum control. Taken together, this data validated the antibody and confirmed incorporation of the C-terminal HA-tag on PfCoronin. Visualization of PfCoroninHA in parasites in late stage schizonts revealed a distribution predominantly at the periphery of the merozoites within the schizont (Figure 6e). Co-labelling of schizonts with antibodies against PfGAP45, a myosin motor accessory proteins that is bound to the outer face of the IMC and plasma membrane [5], and PfACTI, which is known to concentrate to the parasite periphery [10], demonstrated a broadly consistent spatial localization of both proteins within the pellicular space (Figure 6e).

Many proteins that show a pellicular localization in schizonts will re-distribute during merozoite invasion, indicating their involvement in the tight junction or the acto-myosin motor, such as PfAMA1 and PfACTI [10, 41]. To determine if PfCoroninHA redistributed during invasion, invading merozoites captured early, mid and late in the invasion process were co-labelled with RON4, a marker of the tight junction ring (Figure 7a) [41]. The localization of PfCoroninHA, in contrast to expectations, was stable throughout the invasion process with no major redistribution occurring. Co-localization of PfCoroninHA with PfACT1 during 


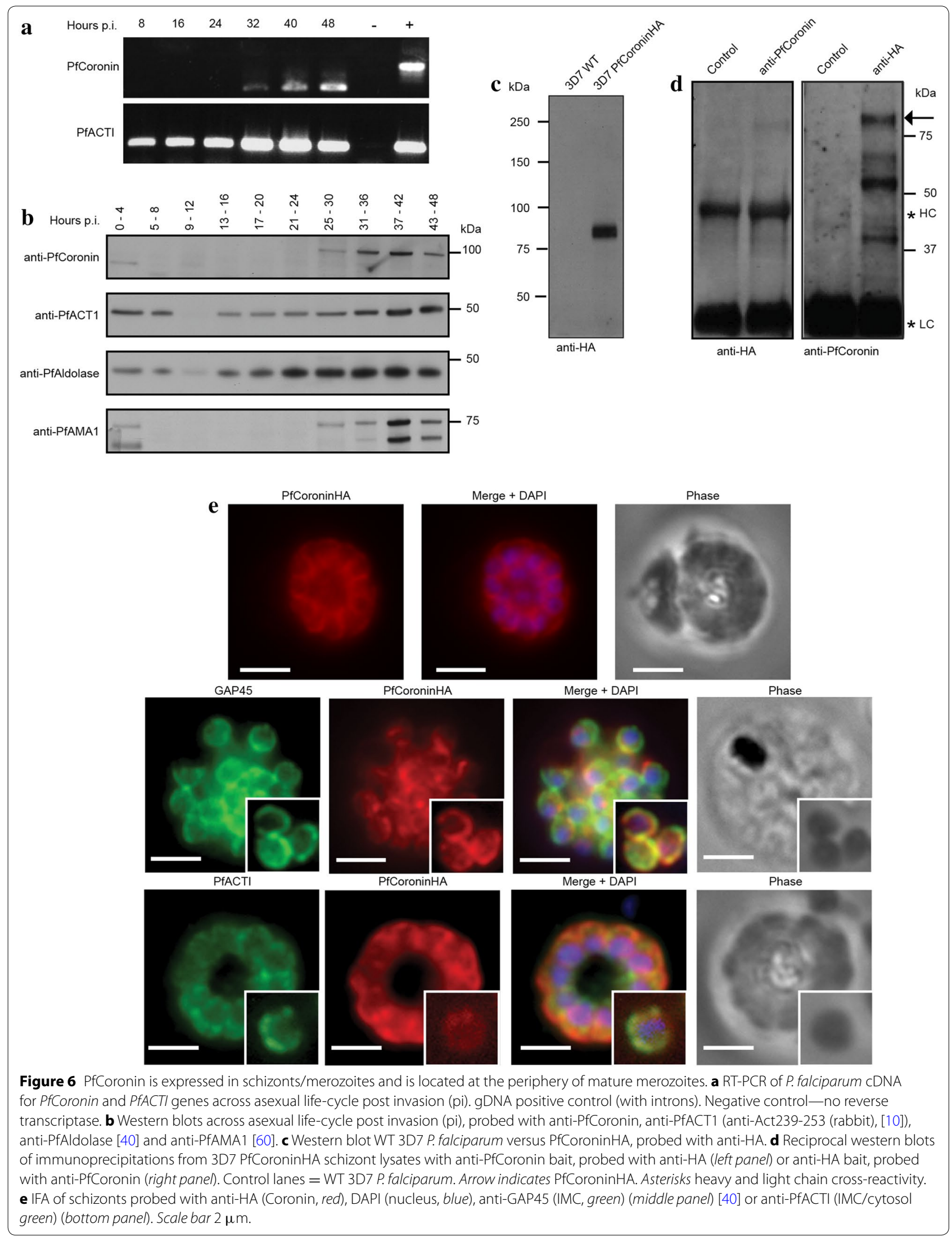




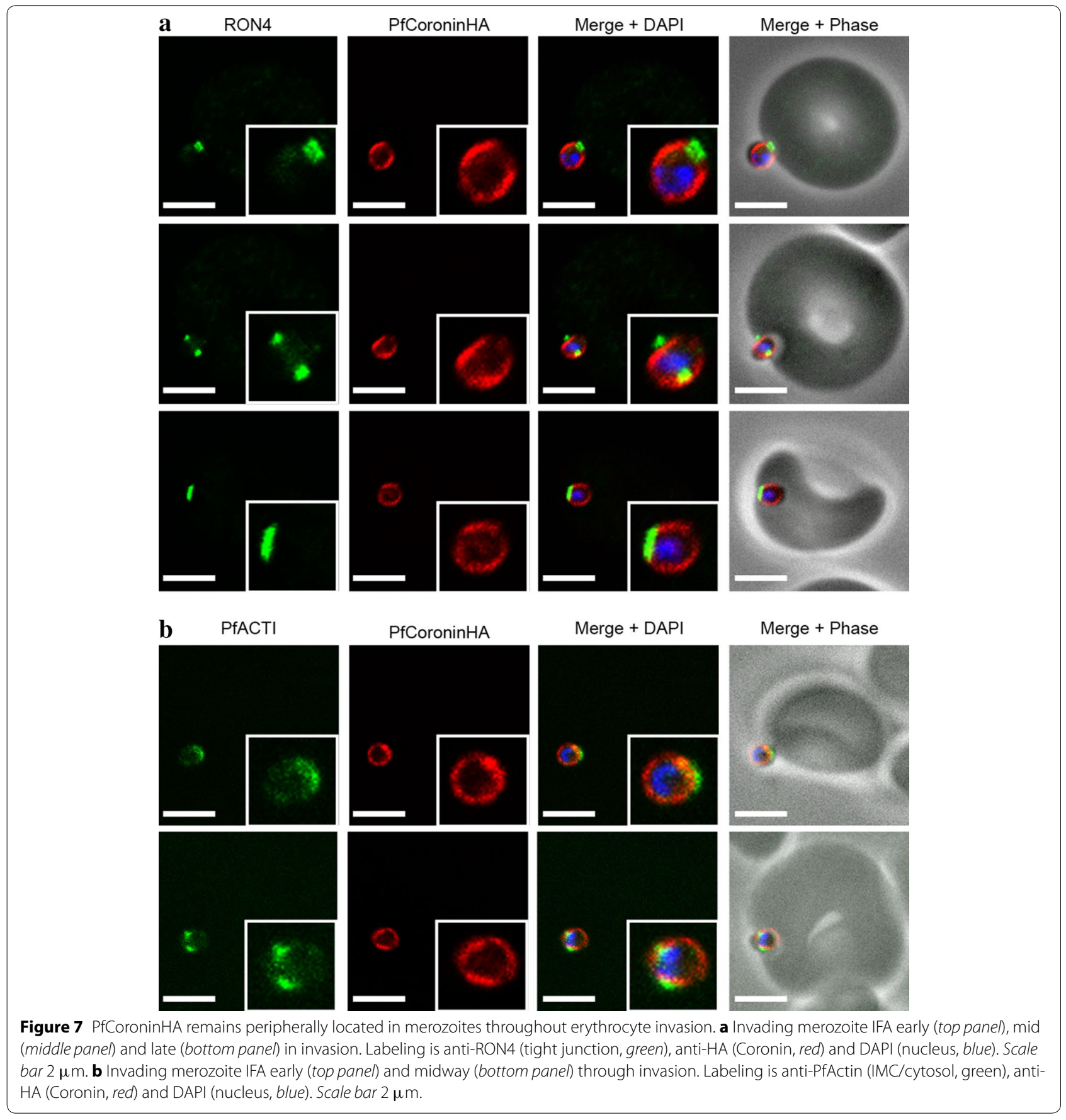

invasion did not reveal any striking correlation with that of F-actin (the major epitope of the Act239-253 antibody) [10] (Figure 7b). Thus PfCoronin appears to occupy a fixed localization at the pellicle of invasive merozoites during their entry into the erythrocyte.

\section{Membrane association of PfCoronin is likely via $\mathrm{PI}(4,5) \mathrm{P}_{2}$ binding}

Since PfCoronin lacks any obvious post-translational lipidation motifs or a transmembrane domain, the nature of the peripheral localization of PfCoroninHA in merozoites was explored. Towards this, purified merozoites were subjected to hypotonic lysis followed by centrifugation to separate cytoplasmic proteins from those that are membrane associated. The membrane-associated fraction was then treated with $\mathrm{Na}_{2} \mathrm{CO}_{3}$ to allow discrimination between integral membrane proteins and those that are associated with membranes. Western blot analysis demonstrated that approximately $40 \%$ of PfCoroninHA is membrane-associated (Figure 8a). As 


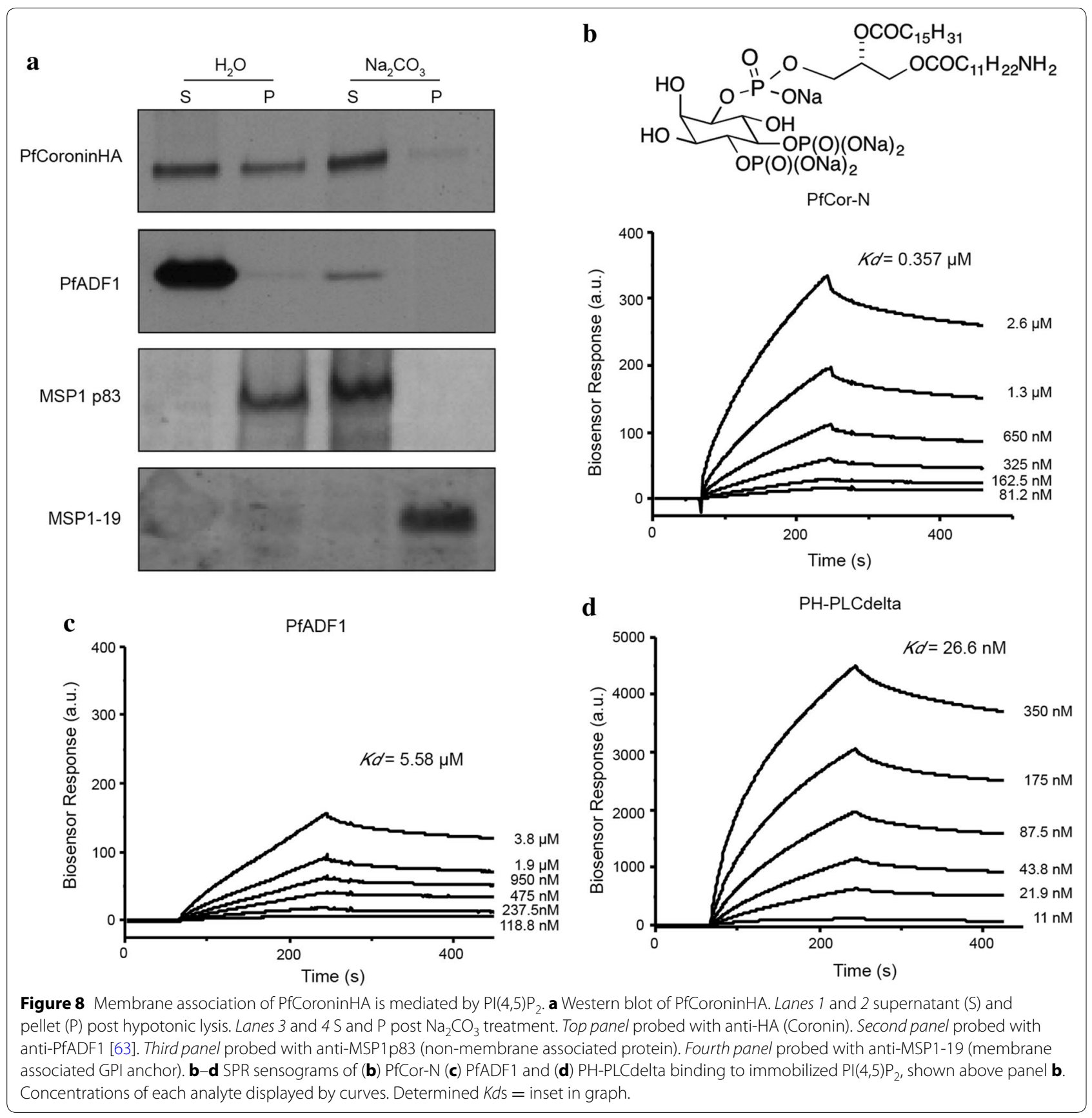

controls, the samples were also probed with antibodies against PfADF1, a soluble cytoplasmic protein [63], GPI-anchored MSP1-19 which remains in the pellet [64], and MSP1p83, a cleaved membrane associated product which is lost to the supernatant post carbonate treatment (Figure 8a) [64]. PfCoroninHA was found in the carbonate-dependent supernatant confirming that whilst not directly integrated into the membrane, it is bound via alternate means.
Coronin proteins from other eukaryotes have been shown to associate with cellular membranes via interaction with phosphatidylinositol 4,5-bisphosphate (PI $(4,5)$ $\mathrm{P}_{2}$ ) [65]. This was tested using recombinant PfCor-N, measuring its affinity for $\mathrm{PI}(4,5) \mathrm{P}_{2}$ via Surface Plasmon Resonance (SPR) with chip-bound amino-terminal $\mathrm{PI}(4,5) \mathrm{P}_{2}$. As controls, PfADF1, a Plasmodium actin binding protein that does not have strong affinity for phosphatidylinositol derivatives [63], and the $\mathrm{PH}$ 
domain of Phospholipase C delta (PH-PLCdelta), a well defined $\mathrm{PI}(4,5) \mathrm{P}_{2}$ binding protein $[66]$ were also tested. Calculation of the $K d$ for each protein revealed values of $0.36 \mu \mathrm{M}$ for PfCor-N, $5.5 \mu \mathrm{M}$ for PfADF1 and $27 \mathrm{nM}$ for PH-PLCdelta (Figure 8b-d). This establishes that PfCor$\mathrm{N}$ binds to $\mathrm{PI}(4,5) \mathrm{P}_{2}$ with sub-micromolar affinity. Combined with IFA determined localization of PfCoroninHA, this data supports the notion that PfCoronin associates with the parasite plasma membrane likely via interaction with resident phospholipids. Placement in this compartment with other components of the motor complex combined with biochemical data is consistent with PfCoronin playing an organizing role for actin during Plasmodium blood stage cell motility.

\section{Discussion}

Apicomplexan gliding and host cell invasion are known to be reliant on a conserved actomyosin motor that generates the force necessary for directional motility. This motor requires dynamic actin filaments, anchored in the parasite pellicular space, to provide a track along which myosin can engage and drive forward cell motion. The actin filaments at the core of the motor are short, unstable and highly dynamic with unusual kinetics [67-73]. Furthermore, they show no evidence of forming any ordered actin structure within the parasite cell $[9,10]$. Indeed, current evidence suggests that the majority of actin in cells is monomeric, with only $\sim 2 \%$ predicted to be incorporated into filaments [74]. Indeed, their highly dynamic nature is essential for functional motility, as treatment of parasites with actin inhibitors impedes host cell invasion and gliding motility [13, 14, 75, 76]. Given such dynamics there is still a major gap in current understanding as to how directional motility, specifically the provision of oriented actin microfilament tracks for myosin, is achieved.

Until recently, it was believed that part of the process of motor engagement, and potentially a major organizing component, came from anchoring of actin filaments to secreted adhesins via the tetrameric enzyme fructose 1,6 bisphosphate aldolase [7]. Indeed several adhesins from the thrombospondin related anonymous protein (TRAP) family $[7,40,77]$ and other unrelated proteins [47, 78] have been independently linked to aldolase. However, recent evidence suggests that whilst the binding may occur readily in vitro (via pull downs) or in the native cell, the interaction in vivo is not a functional requirement for normal motility. Rather it is primarily involved in energy metabolism in the parasite cell [11]. Thus whilst its role in recruiting energy sources to regions of motor activity may still be critical to motility, it may not play any organizing role in the motor. These observations highlight the clear lack in understanding about the entire organization of the motor complex and how it leads to directional force and movement. Evidence presented here suggests coronin as a first organizing factor that links F-actin with the parasite plasma membrane, arranging these into parallel bundles and as such contributing directly to directed gliding motility.

Here, evidence clearly describes the ability of the $\beta$-propeller domain of PfCoronin to bundle actin filaments together using bulk biochemical assays and multiple microscopic techniques. The filament-bundling capacity is somewhat surprising, as previous reports of bundling by other coronins required homo-oligomerization mediated by the C-terminal CC domain to bring multiple actin filaments together into a bundle [30, 32, 53, 79]. However, recent mutational studies have identified multiple binding sites for F-actin on coronin [48, 49], which form a ridge that spans the length of the $\beta$-propeller domain [49]. It has been postulated that these multiple binding sites could be interacting with two or more actin monomers within the filament $[49,80]$, or perhaps, given the results of this study, with two or more monomers from different filaments. Further mutational analysis of the actin binding sites in PfCoronin will be essential to address this phenomenon of $\mathrm{F}$-actin bundling by monomeric coronin.

In vivo, PfCoronin was shown to display a peripheral localization, consistent with the pellicle space (Figure 6e). This data, in combination with a peak of protein expression in maturing and invading merozoites (Figure 6a, b), alludes to a role for PfCoronin in the invasion process. However, the consistent spread of PfCoronin at the parasite periphery during invasion suggests that this role is not limited to linking actin filaments to the plasma membrane at regions of known motor engagement (Figure 7). Indeed, the interaction of PfCor- $\mathrm{N}$ with $\mathrm{PI}(4,5) \mathrm{P}_{2}$ in vitro suggests that the linkage between actin and the membrane may be more direct than previously envisaged. Rather than actin linking via exclusive interactions with tetrameric aldolase to the tails of secreted surface adhesins [7] the entire track for myosin force generation may be bound to the plasma membrane or sub-domains within it. Whilst the caveats of PfCor-N interactions with vertebrate actin need to be verified with a reliable source of correctly folded Plasmodium actin, if validated, the bundling ability of the protein combined with its in vivo distribution would suggest that native PfCoronin may be constantly organizing actin into ordered arrays underlying the plasma membrane, which are temporarily stabilized during motor engagement, permitting any associated adhesin to facilitate the transmission of motor force. Such a scenario would make the apicomplexan actomyosin motor look more muscle-like with an organized face at the IMC side of the pellicular space dedicated to myosin motor organization, and at the plasma membrane 
arrayed patches of parallel-bundled actin filaments ready for myosin engagement. Further mutational, optical and detergent extraction approaches may provide insights into this organization in support of such a model.

Although PfCoronin may be providing an organizing template for motility, there is still a need to explain how myosin motor force is directed and how actin filament polarity is determined within the context of the pellicular space. A portion of directionality determination may fall to the other actin regulators, such as the formins [18]. Further work in this area is clearly needed. In addition, the exact contribution of PfCoronin to parasite motility, the effect PfCoronin binding to actin (and importantly native actin) has on the myosin motor and further comprehensive genetic dissection in P. falciparum, via knockout, conditional knockdown or expression of domain deletions, will be important for understanding the overall regulation of the spatial organization of actin in the parasite pellicle, and consequently the mechanics of host-cell invasion and directional gliding motility.

\section{Conclusion}

In summary, evidence is presented demonstrating actin filament bundling by PfCoronin in vitro that, combined with in vivo imaging data and phospholipid binding, supports a role for PfCoronin being an important effector for organizing actin filaments in the invasive malaria parasite. If validated this would open up the possibility that Coronin across apicomplexan parasites, and across Plasmodium life cycle stages, may be a key organizing force for directional actin filaments and by extension gliding motility in these key human pathogens.

\section{Additional files}

Additional file 1: Movie S1. TIRF OG-Actin alone. The movie demonstrates TIRF microscopy of actin filaments polymerising alone.

Additional file 2: Movie S2. TIRF OG-Actin plus PfCoronin, full view. The movie demonstrates TIRF microscopy of actin filaments polymerising in the presence of PfCoronin- $\mathrm{N}$ terminal protein.

Additional file 3: Movie S3. TIRF OG-Actin plus PfCoronin, zoom view I. The movie demonstrates TIRF microscopy of actin filaments polymerising in the presence of PfCoronin- $\mathrm{N}$ terminal protein zoomed into demonstrate a first example of parallel filament-bundling.

Additional file 4: Movie S4. TIRF OG-Actin plus PfCoronin, zoom view II. The movie demonstrates TIRF microscopy of actin filaments polymerising in the presence of PfCoronin-N terminal protein zoomed into demonstrate a second example of parallel filament-bundling.

Additional file 5: Movie S5. TIRF OG-Actin plus Fimbrin, parallel filaments. The movie demonstrates TIRF microscopy of actin filaments polymerising in the presence of purified Fimbrin, demonstrating parallel bundling of filaments.

Additional file 6: Movie S6. TIRF OG-Actin plus Fimbrin, anti-parallel filaments. The movie demonstrates TIRF microscopy of actin filaments polymerising in the presence of purified Fimbrin, demonstrating antiparallel bundling of filaments.

\section{Abbreviations}

PfCor-N: PfCoronin residues 1-388; ADF: actin depolymerizing factor; RSMA: rabbit skeletal muscle actin; TIRF microscopy: total internal reflection fluorescence; IMC: inner membrane complex.

\section{Authors' contributions}

All authors worked closely together to design and interpret experiments and edit the final manuscript; Experiments were performed by MAO, FA, DSM, DTR, WW, BC, TC. MAO and JB wrote the core paper. All authors read and approved the final manuscript.

\section{Author details}

${ }^{1}$ Infection and Immunity Division, Walter and Eliza Hall Institute of Medical Research, Parkville, VIC 3052, Australia. ${ }^{2}$ Department of Medical Biology, University of Melbourne, Parkville, VIC 3052, Australia. ${ }^{3}$ Department of Infectious Diseases, University of Heidelberg Medical School, Heidelberg, Germany. ${ }^{4}$ Ludwig Institute for Cancer Research, Melbourne Tumour Biology Branch, Royal Melbourne Hospital, Parkville, VIC 3052, Australia. ${ }^{5}$ School of Chemistry, Bio21 Institute, University of Melbourne, Parkville, VIC 3010, Australia. ${ }^{6}$ Department of Molecular Genetics and Cell Biology, The University of Chicago, Chicago, USA. ${ }^{7}$ Department of Biochemistry and Molecular Biology, The University of Chicago, Chicago, USA. ${ }^{8}$ Department of Life Sciences, Imperial College London, Sir Alexander Fleming Building, Level 6, South Kensington, London SW72AZ, UK. ${ }^{9}$ Present Address: Department of Systems Biology, Harvard Medical School, 200 Longwood Ave WAB 536, Boston, MA 02115 , USA. ${ }^{10}$ Present Address: Systems Biology and Personalised Medicine Division, Walter and Eliza Hall Institute of Medical Research, Parkville, VIC 3052, Australia.

\section{Acknowledgements}

We thank Jacqui Gulbis for ongoing support and advice throughout the projects duration. We also thank Jenna Christensen (for provision of recombinant Fimbrin) and Dennis Zimmerman, Cristian Suarez and Yujie Li for invaluable assistance with TIRF microscopy. We thank Alan Yap for providing P. falciparum genomic DNA, Teresa Carvalho for help with vector construction and Anthony Hodder for providing the pProEX-HTB plasmid. Experimental data presented here was made possible through Victorian State Government Operational Infrastructure Support and Australian Government NHMRC IRIISS. The research was directly supported by a National Health and Medical Research Council of Australia (NHMRC) Project Grant (APP1024678 JB), Human Frontier Science Program (HFSP) Young Investigator Program Grant (JB DRK and FF, RGY0071/2011), Australian Research Council (ARC) Discovery Project Grant (ABH BC MXY DP1094497) and the European Union FP7 network of excellence EVIMalaR (FF). DR was supported by a Pratt Foundation postgraduate scholarship through the University of Melbourne. MAO and FA are supported through NHMRC Dora Lush Scholarships (APP1018002 and APP1055246). MAO was supported with travel awards from The University of Melbourne Overseas Research Experience Scholarship, the Australian Society of Parasitology JD Smyth Postgraduate Travel Award and the Australian Society for Biochemistry and Molecular Biology. WW is supported through an Early Career Fellowship (APP1053801) from the NHMRC. FF was supported by the Chica and Heinz Schaller foundation. JB was supported through a Future Fellowship (FT100100112) from the ARC and is currently supported by the Wellcome Trust, through a New Investigator Award (100993/Z/13/Z).

\section{Compliance with ethical guidelines}

\section{Competing interests}

The authors declare that they have no competing interests.

Received: 15 June 2015 Accepted: 4 July 2015

Published online: 18 July 2015

\section{References}

1. Cowman AF, Berry D, Baum J (2012) The cellular and molecular basis for malaria parasite invasion of the human red blood cell. J Cell Biol 198:961-971

2. Prudencio M, Rodriguez A, Mota MM (2006) The silent path to thousands of merozoites: the Plasmodium liver stage. Nat Rev Microbiol 4:849-856 
3. Baum J, Gilberger T-W, Frischknecht F, Meissner M (2008) Host-cell invasion by malaria parasites: insights from Plasmodium and Toxoplasma. Trends Parasitol 24:557-563

4. Morrissette NS, Sibley LD (2002) Cytoskeleton of apicomplexan parasites. Microbiol Mol Biol Rev 66:21-38

5. Frénal K, Polonais V, Marq J-B, Stratmann R, Limenitakis J, Soldati-Favre D (2010) Functional dissection of the apicomplexan glideosome molecular architecture. Cell Host Microbe 8:343-357

6. Pinder JC, Fowler RE, Dluzewski AR, Bannister LH, Lavin FM, Mitchell GH et al (1998) Actomyosin motor in the merozoite of the malaria parasite, Plasmodium falciparum: implications for red cell invasion. J Cell Sci 111:1831-1839

7. Jewett TJ, Sibley LD (2003) Aldolase forms a bridge between cell surface adhesins and the actin cytoskeleton in apicomplexan parasites. Mol Cell 11:885-894

8. Wang J, Morris AJ, Tolan DR, Pagliaro L (1996) The molecular nature of the F-actin binding activity of aldolase revealed with site-directed mutants. J Biol Chem 271:6861-6865

9. Kudryashev M, Lepper S, Baumeister W, Cyrklaff M, Frischknecht F (2010) Geometric constrains for detecting short actin filaments by cryogenic electron tomography. PMC Biophys 3:6

10. Angrisano F, Riglar DT, Sturm A, Volz JC, Delves MJ, Zuccala ES et al (2012) Spatial localisation of actin filaments across developmental stages of the malaria parasite. PLoS One 7:e32188

11. Shen B, Sibley LD (2014) Toxoplasma aldolase is required for metabolism but dispensable for host-cell invasion. Proc Natl Acad Sci USA 111:3567-3572

12. Egarter S, Andenmatten N, Jackson AJ, Whitelaw JA, Pall G, Black JA et al (2014) The Toxoplasma Acto-MyoA motor complex is important but not essential for gliding motility and host cell invasion. PLoS One 9:e91819

13. Miller LH, Aikawa M, Johnson JG, Shiroishi T (1979) Interaction between cytochalasin B-treated malarial parasites and erythrocytes. Attachment and junction formation. J Exp Med 149:172-184

14. Mizuno Y, Makioka A, Kawazu S, Kano S, Kawai S, Akaki M et al (2002) Effect of jasplakinolide on the growth, invasion, and actin cytoskeleton of Plasmodium falciparum. Parasitol Res 88:844-848

15. Schuler H, Matuschewski K (2006) Regulation of apicomplexan microfilament dynamics by a minimal set of actin-binding proteins. Traffic 7:1433-1439

16. Baum J, Papenfuss AT, Baum B, Speed TP, Cowman AF (2006) Regulation of apicomplexan actin-based motility. Nat Rev Microbiol 4:621-628

17. Olshina MA, Wong W, Baum J (2012) Holding back the microfilamentstructural insights into actin and the actin-monomer-binding proteins of apicomplexan parasites. IUBMB Life 64:370-377

18. Baum J, Tonkin CJ, Paul AS, Rug M, Smith BJ, Gould SB et al (2008) A malaria parasite formin regulates actin polymerization and localizes to the parasite-erythrocyte moving junction during invasion. Cell Host Microb 3:188-198

19. Kursula I, Kursula P, Ganter M, Panjikar S, Matuschewski K, Schuler H (2008) Structural basis for parasite-specific functions of the divergent profilin of Plasmodium falciparum. Structure 16:1638-1648

20. Wong W, Webb Al, Olshina MA, Infusini G, Tan YH, Hanssen E et al (2014) A mechanism for actin filament severing by malaria parasite actin depolymerizing factor 1 via a low affinity binding interface. J Biol Chem 289:4043-4054

21. Singh BK, Sattler JM, Chatterjee M, Huttu J, Schüler H, Kursula I (2011) Crystal structures explain functional differences in the two actin depolymerization factors of the malaria parasite. J Biol Chem 286:28256-28264

22. Makkonen M, Bertling E, Chebotareva NA, Baum J, Lappalainen P (2013) Mammalian and malaria parasite cyclase-associated proteins catalyze nucleotide exchange on G-actin through a conserved mechanism. J Biol Chem 288:984-994

23. Hliscs M, Sattler JM, Tempel W, Artz JD, Dong A, Hui R et al (2010) Structure and function of a G-actin sequestering protein with a vital role in malaria oocyst development inside the mosquito vector. J Biol Chem 285:11572-11583

24. Ganter M, Rizopoulos Z, Schuler H, Matuschewski K (2015) Pivotal and distinct role for Plasmodium actin capping protein alpha during blood infection of the malaria parasite. Mol Microbiol 96:84-94
25. Tardieux I, Liu X, Poupel O, Parzy D, Dehoux P, Langsley G (1998) A Plasmodium falciparum novel gene encoding a coronin-like protein which associates with actin filaments. FEBS Lett 441:251-256

26. Uetrecht AC, Bear JE (2006) Coronins: the return of the crown. Trends Cell Biol 16:421-426

27. Eckert C, Hammesfahr B, Kollmar M (2011) A holistic phylogeny of the coronin gene family reveals an ancient origin of the tandem-coronin, defines a new subfamily, and predicts protein function. BMC Evol Biol $11: 268$

28. Chan KT, Creed SJ, Bear JE (2011) Unraveling the enigma: progress towards understanding the coronin family of actin regulators. Trends Cell Biol 21:481-488

29. Appleton BA, Wu P, Wiesmann C (2006) The crystal structure of murine coronin-1: a regulator of actin cytoskeletal dynamics in lymphocytes. Structure 14:87-96

30. Gatfield J, Albrecht I, Zanolari B, Steinmetz MO, Pieters J (2005) Association of the leukocyte plasma membrane with the actin cytoskeleton through coiled coil-mediated trimeric coronin 1 molecules. Mol Biol Cell 16:2786-2798

31. Kammerer RA, Kostrewa D, Progias P, Honnappa S, Avila D, Lustig A et al (2005) A conserved trimerization motif controls the topology of short coiled coils. Proc Natl Acad Sci USA 102:13891-13896

32. Salamun J, Kallio JP, Daher W, Soldati-Favre D, Kursula I (2014) Structure of Toxoplasma gondii coronin, an actin-binding protein that relocalizes to the posterior pole of invasive parasites and contributes to invasion and egress. FASEB J 28:4729-4747

33. Spudich JA, Watt S (1971) The regulation of rabbit skeletal muscle contraction. I. Biochemical studies of the interaction of the tropomyosintroponin complex with actin and the proteolytic fragments of myosin. J Biol Chem 246:4866-4871

34. Wachsstock DH, Schwartz WH, Pollard TD (1993) Affinity of alpha-actinin for actin determines the structure and mechanical properties of actin filament gels. Biophys J 65:205-214

35. Neirynck K, Waterschoot D, Vandekerckhove J, Ampe C, Rommelaere $H$ (2006) Actin interacts with CCT via discrete binding sites: a binding transition-release model for CCT-mediated actin folding. J Mol Biol 355:124-138

36. de Chaumont F, Dallongeville S, Chenouard N, Herve N, Pop S, Provoost T et al (2012) Icy: an open bioimage informatics platform for extended reproducible research. Nat Methods 9:690-696

37. Kovar DR, Kuhn JR, Tichy AL, Pollard TD (2003) The fission yeast cytokinesis formin Cdc12p is a barbed end actin filament capping protein gated by profilin. J Cell Biol 161:875-887

38. Neidt EM, Skau CT, Kovar DR (2008) The cytokinesis formins from the nematode worm and fission yeast differentially mediate actin filament assembly. J Biol Chem 283:23872-23883

39. Boyle MJ, Wilson DW, Richards JS, Riglar DT, Tetteh KK, Conway DJ et al (2010) Isolation of viable Plasmodium falciparum merozoites to define erythrocyte invasion events and advance vaccine and drug development. Proc Natl Acad Sci USA 107:14378-14383

40. Baum J, Richard D, Healer J, Rug M, Krnajski Z, Gilberger T-W et al (2006) A conserved molecular motor drives cell invasion and gliding motility across malaria life cycle stages and other apicomplexan parasites. J Biol Chem 281:5197-5208

41. Riglar DT, Richard D, Wilson DW, Boyle MJ, Dekiwadia C, Turnbull L et al (2011) Super-resolution dissection of coordinated events during malaria parasite invasion of the human erythrocyte. Cell Host Microbe 9:9-20

42. Lambros C, Vanderberg JP (1979) Synchronization of Plasmodium falciparum erythrocytic stages in culture. J Parasitol 65:418-420

43. Boyle MJ, Richards JS, Gilson PR, Chai W, Beeson JG (2010) Interactions with heparin-like molecules during erythrocyte invasion by Plasmodium falciparum merozoites. Blood 115:4559-4568

44. Richard D, MacRaild CA, Riglar DT, Chan J-A, Foley M, Baum J et al (2010) Interaction between Plasmodium falciparum apical membrane antigen 1 and the rhoptry neck protein complex defines a key step in the erythrocyte invasion process of malaria parasites. J Biol Chem 285:14815-14822

45. Conway SJ, Gardiner J, Grove SJ, Johns MK, Lim ZY, Painter GF et al (2010) Synthesis and biological evaluation of phosphatidylinositol phosphate affinity probes. Org Biomol Chem 8:66-76

46. Catimel B, Kapp E, Yin MX, Gregory M, Wong LS, Condron M et al (2013) The PI(3)P interactome from a colon cancer cell. J Proteomics 82:35-51 
47. Diaz SA, Martin SR, Grainger M, Howell SA, Green JL, Holder AA (2014) Plasmodium falciparum aldolase and the C-terminal cytoplasmic domain of certain apical organellar proteins promote actin polymerization. Mol Biochem Parasitol 197:9-14

48. Chan KT, Roadcap DW, Holoweckyj N, Bear JE (2012) Coronin 1C harbours a second actin-binding site that confers co-operative binding to F-actin. Biochem J 444:89-96

49. Gandhi M, Jangi M, Goode BL (2010) Functional surfaces on the actinbinding protein coronin revealed by systematic mutagenesis. J Biol Chem 285:34899-34908

50. Skau CT, Courson DS, Bestul AJ, Winkelman JD, Rock RS, Sirotkin $\checkmark$ et al (2011) Actin filament bundling by fimbrin is important for endocytosis, cytokinesis, and polarization in fission yeast. J Biol Chem 286:26964-26977

51. Xu J, Wirtz D, Pollard TD (1998) Dynamic cross-linking by alpha-actinin determines the mechanical properties of actin filament networks. J Biol Chem 273:9570-9576

52. Falzone TT, Lenz M, Kovar DR, Gardel ML (2012) Assembly kinetics determine the architecture of alpha-actinin crosslinked F-actin networks. Nat Commun 3:861

53. Goode BL, Wong JJ, Butty AC, Peter M, McCormack AL, Yates JR et al (1999) Coronin promotes the rapid assembly and cross-linking of actin filaments and may link the actin and microtubule cytoskeletons in yeast. J Cell Biol 144:83-98

54. Asano S, Mishima M, Nishida E (2001) Coronin forms a stable dimer through its C-terminal coiled coil region: an implicated role in its localization to cell periphery. Genes Cells 6:225-235

55. Tempel M, Isenberg G, Sackmann E (1996) Temperature-induced sol-gel transition and microgel formation in alpha-actinin cross-linked actin networks: a rheological study. Phys Rev E Stat Phys Plasmas Fluids Relat Interdiscip Topics 54:1802-1810

56. Higaki T, Kutsuna N, Sano T, Kondo N, Hasezawa S (2010) Quantification and cluster analysis of actin cytoskeletal structures in plant cells: role of actin bundling in stomatal movement during diurnal cycles in Arabidopsis quard cells. Plant J 61:156-165

57. Khurana P, Henty JL, Huang S, Staiger AM, Blanchoin L, Staiger CJ (2010) Arabidopsis VILLIN1 and VILLIN3 have overlapping and distinct activities in actin bundle formation and turnover. Plant Cell 22:2727-2748

58. Bozdech Z, Zhu J, Joachimiak MP, Cohen FE, Pulliam B, DeRisi JL (2003) Expression profiling of the schizont and trophozoite stages of Plasmodium falciparum with a long-oligonucleotide microarray. Genome Biol 4:R9

59. Gardner MJ, Hall N, Fung E, White O, Berriman M, Hyman RW et al (2002) Genome sequence of the human malaria parasite Plasmodium falciparum. Nature 419:498-511

60. Hodder AN, Crewther PE, Anders RF (2001) Specificity of the protective antibody response to apical membrane antigen 1. Infect Immun 69:3286-3294

61. Crewther PE, Culvenor JG, Silva A, Cooper JA, Anders RF (1990) Plasmodium falciparum: two antigens of similar size are located in different compartments of the rhoptry. Exp Parasitol 70:193-206

62. Triglia T, Healer J, Caruana SR, Hodder AN, Anders RF, Crabb BS et al (2000) Apical membrane antigen 1 plays a central role in erythrocyte invasion by Plasmodium species. Mol Microbiol 38:706-718

63. Wong W, Skau CT, Marapana DS, Hanssen E, Taylor NL, Riglar DT et al (2011) Minimal requirements for actin filament disassembly revealed by structural analysis of malaria parasite actin-depolymerizing factor 1. Proc Natl Acad Sci USA 108:9869-9874

64. Kauth CW, Woehlbier U, Kern M, Mekonnen Z, Lutz R, Mucke N et al (2006) Interactions between merozoite surface proteins 1, 6, and 7 of the malaria parasite Plasmodium falciparum. J Biol Chem 281:31517-31527
65. Tsujita K, Itoh T, Kondo A, Oyama M, Kozuka-Hata H, Irino Y et al (2010) Proteome of acidic phospholipid-binding proteins: spatial and temporal regulation of Coronin $1 \mathrm{~A}$ by phosphoinositides. J Biol Chem 285:6781-6789

66. Catimel B, Schieber C, Condron M, Patsiouras H, Connolly L, Catimel J et al (2008) The PI(3,5)P2 and PI(4,5)P2 interactomes. J Proteome Res 7:5295-5313

67. Schüler H, Mueller A-K, Matuschewski K (2005) Unusual properties of Plasmodium falciparum actin: new insights into microfilament dynamics of apicomplexan parasites. FEBS Lett 579:655-660

68. Schmitz S, Schaap IA, Kleinjung J, Harder S, Grainger M, Calder L et a (2010) Malaria parasite actin polymerization and filament structure. J Biol Chem 285:36577-36585

69. Schmitz S, Grainger M, Howell S, Calder LJ, Gaeb M, Pinder JC et al (2005) Malaria parasite actin filaments are very short. J Mol Biol 349:113-125

70. Vahokoski J, Bhargav SP, Desfosses A, Andreadaki M, Kumpula EP, Martinez SM et al (2014) Structural differences explain diverse functions of Plasmodium actins. PLoS Pathog 10:e1004091

71. Skillman KM, Ma Cl, Fremont DH, Diraviyam K, Cooper JA, Sept D et al (2013) The unusual dynamics of parasite actin result from isodesmic polymerization. Nat Commun 4:2285

72. Skillman KM, Diraviyam K, Khan A, Tang K, Sept D, Sibley LD (2011) Evolutionarily divergent, unstable filamentous actin is essential for gliding motility in apicomplexan parasites. PLoS Pathog 7:e1002280

73. Sahoo N, Beatty W, Heuser J, Sept D, Sibley LD (2006) Unusual kinetic and structural properties control rapid assembly and turnover of actin in the parasite Toxoplasma gondii. Mol Biol Cell 17:895-906

74. Field SJ, Pinder JC, Clough B, Dluzewski AR, Wilson RJ, Gratzer WB (1993) Actin in the merozoite of the malaria parasite, Plasmodium falciparum. Cell Motil Cytoskelet 25:43-48

75. Dobrowolski JM, Sibley LD (1996) Toxoplasma invasion of mammalian cells is powered by the actin cytoskeleton of the parasite. Cell 84:933-939

76. Wetzel DM, Håkansson S, Hu K, Roos D, Sibley LD (2003) Actin filament polymerization regulates gliding motility by apicomplexan parasites. Mol Biol Cell 14:396-406

77. Bosch J, Turley S, Roach CM, Daly TM, Bergman LW, Hol WG (2007) The closed MTIP-myosin A-tail complex from the malaria parasite invasion machinery. J Mol Biol 372:77-88

78. Sheiner L, Santos JM, Klages N, Parussini F, Jemmely N, Friedrich N et al (2010) Toxoplasma gondii transmembrane microneme proteins and their modular design. Mol Microbiol 77:912-929

79. Oku T, Itoh S, Ishii R, Suzuki K, Nauseef WM, Toyoshima S et al (2005) Homotypic dimerization of the actin-binding protein p57/coronin-1 mediated by a leucine zipper motif in the C-terminal region. Biochem J 387:325-331

80. Galkin VE, Orlova A, Brieher W, Kueh HY, Mitchison TJ, Egelman EH (2008) Coronin-1A stabilizes F-actin by bridging adjacent actin protomers and stapling opposite strands of the actin filament. J Mol Biol 376:607-613

\section{Submit your next manuscript to BioMed Central and take full advantage of:}

- Convenient online submission

- Thorough peer review

- No space constraints or color figure charges

- Immediate publication on acceptance

- Inclusion in PubMed, CAS, Scopus and Google Scholar

- Research which is freely available for redistribution

Submit your manuscript at

www.biomedcentral.com/submit
() Biomed Central 